\title{
Kinetics of drying the titanium dioxide paste in the vortex dryer
}

\section{Victor Marchevskii, Yaroslav Grobovenko, Viktoria Telestakova}

National Technical University of Ukraine "Igor Sikorsky Kyiv Polytechnic Institute"

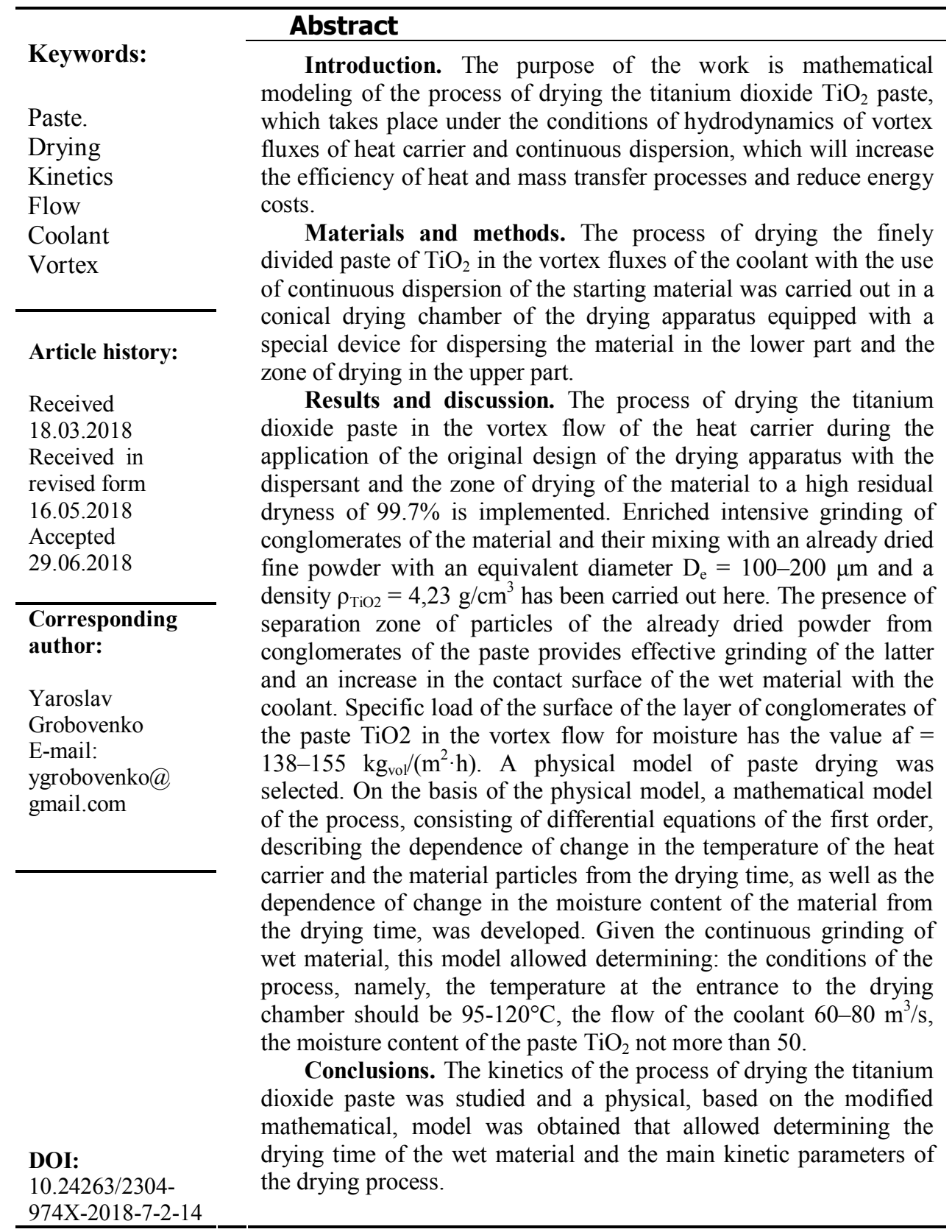




\section{Introduction}

The process of drying finely divided paste is a technological process that consists of a combination of heat transfer processes of heat and mass. When choosing the optimal drying and rational design of the dryer, it is necessary to provide the conditions necessary for obtaining the technological properties of the material, which require industry standards. The rational method of heat treatment and the most suitable design of drying apparatus are established only for a particular material or group of materials having similar physical and chemical properties. In this paper, as a material, a finely divided titanium dioxide titanium dioxide $\mathrm{TiO}_{2}$ is considered.

An important scientific challenge is to reduce the cost of heat energy in the drying process, which consumes up to $25 \%$ of world energy production [1]. An insufficiently solved problem is the reduction of energy costs and the intensification of drying in the production of finely divided powders, in particular titanium dioxide. The market demand for titanium dioxide is increasing. Major consumers of $\mathrm{TiO}_{2}$ titanium dioxide are paint and varnish, metallurgy, paper, pharmaceuticals and other industries where it is used as filler. Titanium dioxide is also used as filler for the manufacture of various plastic masses and products, and for the production of high-quality paper.

In the technology of producing titanium dioxide, the process of drying paste of $\mathrm{TiO}_{2}$ is the most energy-intensive and limiting process [2]. One of the main indicators of finished products is the low residual moisture of fine powder. It should be no more than $0.3 \%$ [3]. To obtain such a value of residual moisture in conventional drying machines, the temperature of the waste heat carrier at the exit of the dryer increases, this leads to significant costs of thermal energy. In the process of drying it is necessary to destroy agglomerates, with stand a narrow range of moisture content, to separate the particles in geometric sizes (remove dust particles), to clean the coolant.

The purpose of experimental research is to determine the conditions under which the process of drying the titanium dioxide paste in the vortex flow of the heat carrier occurs, and the resulting dried product meets the technical requirements.

\section{Choice of dryer type}

The choice of the most appropriate type of apparatus for drying the fine titanium dioxide paste is based on the analysis of a significant number of various factors affecting the drying process, such as $[1,4]$ :

tharacteristics of paste as an object of drying;

productivity of the device;

technological requirements for drying, taking into account all the processes necessary for obtaining high-quality products;

requirements of environmental and industrial sanitation;

energy and economic requirements.

The analysis of literature $[5,6]$ showed that at present the choice of optimal and expedient type of drying apparatus for fine disperse paste is a complex task of the system analysis of processes and apparatuses of chemical technology. Almost such a choice is made on the basis of a quantitative or qualitative assessment of the conformity of known types of apparatus to the properties of the paste. Important such properties are [7]:

- the value of the specific surface, the size and volume of the pores, which determine together the diffusion resistance of the internal mass transfer;

- thermal properties that determine the thermal resistance during drying; 
- the forms of moisture communication with the material, which determine the energy that needs to be spent on drying and affect the heat transfer mechanism;

- hydraulic properties.

Determining the full set of these properties is a complex and bulky task that requires a lot of experimental work. Therefore, in order to expedite the choice of the most appropriate type of dryer, in this work it was decided to assess the existing modern drying equipment for the conformity of the dried product.

After a preliminary assessment of existing drying equipment, many of the presented vehicles preferred a group of dry-cleaners such as "fluidized bed" (FB). This is the most promising group of devices for fine-grained materials $[14,15]$, since only they can provide heat and mass transfer to each individual aggregate unit. This group includes aggregates:

boiling bed (BB) and passage boiling bed (PBB);

type "Flash";

fountain bed (FB) and air fountain bed (AFB);

vibro boiling bed (VBB);

vortex bed (VB);

pneumatic transport (PT);

with twisted streams (TS);

twith counterclockwise twisted streams (CTS).

The selected list of drying appliances should be supplemented with devices with an organized fluidized bed (OFB) and pneumatic helix driers (PHD) [15], as well as combined plants of various types.

Problems of intensification of heat and mass transfer in drying apparatuses for dispersed materials, as well as elimination of the removal of non-material material or reduction of the retour and some other problems characterizing the quality of the chosen drying method and design of the dryer, are determined by the hydrodynamic regime. Hydrodynamics of vortex flows, as well as physical and mathematical modeling of the finegrained drying process, are studied in detail and widely represented in the literature [2, 3].

It is known equations that determine the range of the fluidized bed, namely, expressions for $K=v_{f l} / v_{c r} \operatorname{Re}_{c r} \operatorname{Re}_{f l} K_{\max }$ [9], where $\operatorname{Re}_{c r} \operatorname{Re}_{f l}$ the value of the Reynolds criteria corresponding to the beginning of the fluidization and removal of the material, $v_{c r} v_{f l}$ speeds that determine the relevant criteria $\operatorname{Re}[8,9]$.

The distribution of thermal energy and moisture, for a single particle, along the length of the drying apparatus, is always a complex problem of external and internal heat and mass transfer, which is rather complex and requires considerable computational effort [5]. A simpler approach to finding a change in system parameters is based on the use of a boundary task. The system of equations of internal heat and mass transfer recorded in the framework of the boundary problem in its most general form is represented by formula 1 :

$$
\left\{\begin{array}{c}
\frac{\partial U}{\partial \tau}=a_{m}\left(\frac{\partial^{2} U}{\partial r^{2}}+\frac{\Gamma}{r} \cdot \frac{\partial U}{\partial r}\right)+\frac{\partial a_{m}}{\partial r} \cdot \frac{\partial U}{\partial r}+a_{m} \delta\left(\frac{\partial^{2} T}{\partial r^{2}}+\frac{\Gamma}{r} \cdot \frac{\partial T}{\partial r}\right)+\left(\delta \frac{\partial a_{m}}{\partial r}+a \frac{\partial \delta}{\partial r}\right) \cdot \frac{\partial T}{\partial r} \\
\frac{\partial T}{\partial \tau}=\frac{\lambda}{c_{T} \rho_{T}}\left(\frac{\partial^{2} T}{\partial r^{2}}+\frac{\Gamma}{r} \cdot \frac{\partial T}{\partial r}\right)+\frac{1}{c_{T} \rho_{T}} \cdot \frac{\partial \lambda}{\partial T} \cdot \frac{\partial T}{\partial r}+\frac{\varepsilon r}{c_{T}} \cdot \frac{\partial U}{\partial T}
\end{array},\right.
$$

where $a, a_{m}$ in accordance, thermal conductivity and conductivity. 


\section{Materials and methods}

\section{Materials}

As a drying material, a thyrotrophic fine $\mathrm{TiO}_{2}$ titanium dioxide paste with an initial moisture content of $\mathrm{w}=55 \%$ and a density of $\rho=2173 \mathrm{~kg} / \mathrm{m}^{3}$ was used which, when applied mechanically, reduced its viscosity and increased fluidity. This feature of the paste allows you to feed it into the drying chamber with an increased dryness of up to $80 \%$ and, at the same time, will not clog the feeder-dispenser installation.

\section{Experimental installation}

In order to achieve the prescribed requirements for a dried titanium dioxide powder, a specially designed technique for conducting experiment.

Investigation of the drying process of fine titanium dioxide paste in vortex fluxes of a heat carrier was carried out on a pilot plant with the dimensions of a vortex conical drying chamber $A \times B \times H=0,1 \times 0,4 \times 0,7 \mathrm{~m}$. The vortex chamber of the drying apparatus in the lower part is equipped with a dispersant for grinding agglomerates of paste [Patent of Ukraine № 108688 IPC F26B 17/10 (2006.01)]. Also, the authors of the article developed a method for drying paste-like materials, on which the design of the dryer [Patent of Ukraine № 107089 IPC F26B 17/10 (2006.01)].

\section{Measuring complex}

The pressure difference in the dispersion zone and the pre-drying zone was continuously measured by two difemometers $\mathrm{D}_{2}$ and $\mathrm{D}_{3}$, the power of the dispersant drive was measured by a measuring complex of the K50 type No. 1654, the temperature of the coolant - the diffusion meter $\mathrm{D}_{1}$, the temperature and humidity of the vortex fluxes of the heat carrier and the particles of titanium dioxide by the computerized system at application humidity and temperature sensors MLX90614 with a frequency of 63 measurements per second $(63 \mathrm{~Hz})$ connected to a computer through the Arduino Pro Mini controller. The diagram of the arrangement of devices and sensors for data storage, differential meters and main elements is shown in Fig. 1. 


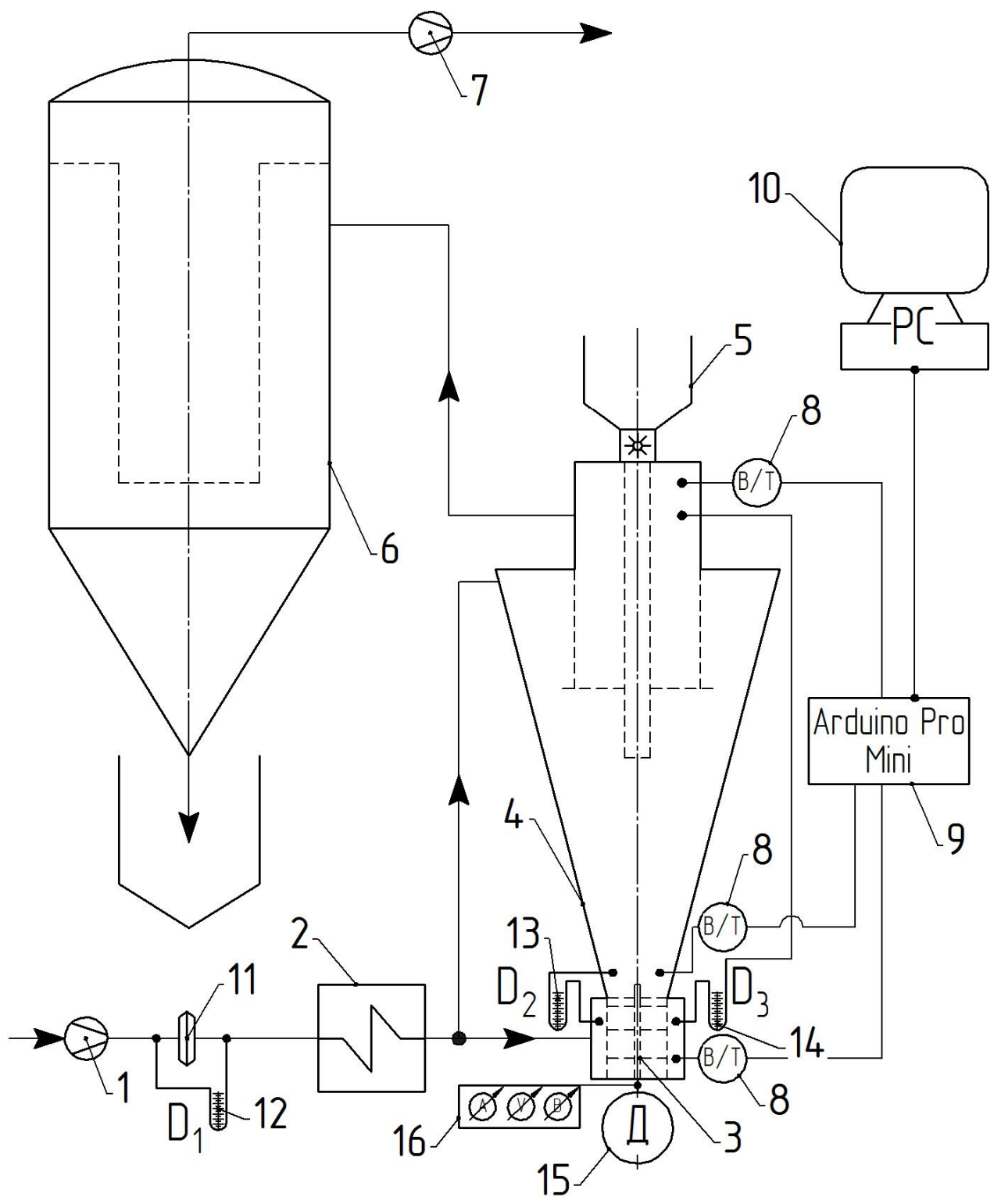

Figure 1. Scheme of a computerized system for measuring pressure drop, power, temperature and humidity in an experimental drying plant:

1, 7 - booster and exhaust fans; 2 - heater; 3 - dispersant; 4 -drying chamber; 5 - feeder-dispenser; 6 - a sleeve filter; 8 - temperature and humidity sensor MLX90614; 9 - Microcontroller Arduino Pro Mini; 10 - computer for visualization and data storage; 11 - diaphragm; $12,13,14$ - difemometer; 15 - electric drive; 16 - measuring complex type K50 №1654 


\section{Results and discussion}

Theoretical studies of trajectories and hydrodynamics of vortex flows of a drying agent in a developed drying chamber

In this paper, the original design of a drying apparatus (Figure 2) is considered for the production of a fine powder of titanium dioxide.

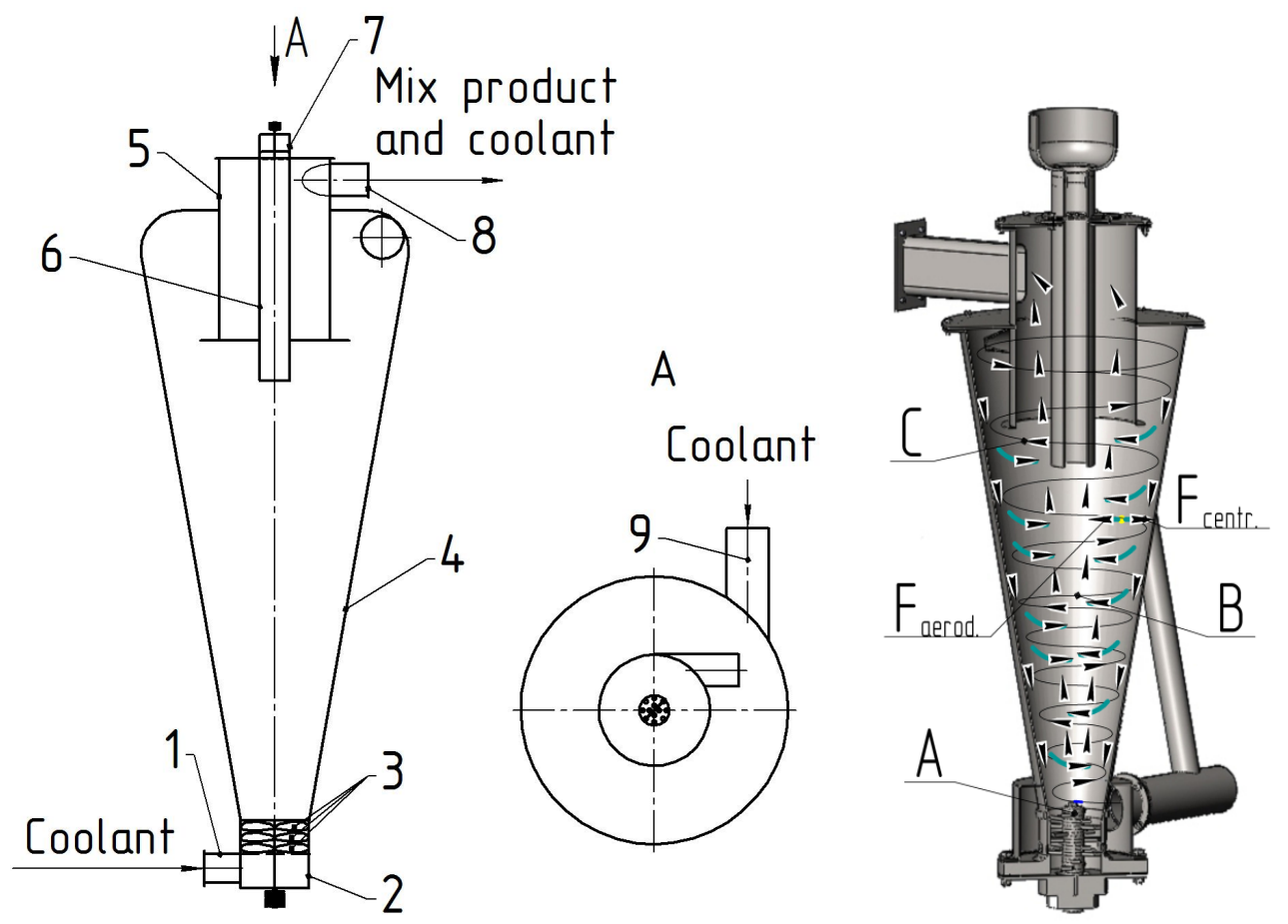

Figure 2. Scheme of the original drying apparatus for obtaining fine dispersions:

1 - the main supply pipe coolant; 2 - diffuser; 3 - dispersant; 4 - Cone-shaped drying chamber; 5 - nozzle for supplying the drying agent to drying; 6 - separation cylinder; 7 - the system of supply of moist dispersions; 8 - outlet pipe; $\mathrm{A}$ - dispersion zone; $\mathrm{B}$ - fractional separation zone; $\mathrm{C}$ - zone of intensive drying

First of all, it is necessary to know the distribution of gas flow between continuous gas and fine material for the development of methods for calculating heat and mass transfer processes when drying fine-grained pastes and the creation of appropriate equipment with two-phase media. These tasks form the basis for describing the behavior of two-phase environments, namely vortex flows, and therefore cause great interest in these problems. However, satisfactory quantitative patterns that adequately reflect the aerodynamic and hydrodynamic characteristics of vortex flows are still rare in the literature.

Two-phase vortical streams arise in the drying chamber, in which a process of drying of a wet product - a finely divided paste of $\mathrm{TiO}_{2}-$ occurs. As a coolant the heated dry air is used at a temperature of $90-120^{\circ} \mathrm{C}$. These flows at each stage play an important role in 
addition to the heat and mass transfer processes, as well as the displacement of solid dispersion over the respective zones of the drying chamber A, B, C (Figure 2).

A 3D model of the drying machine was designed using the Solid Works SolidWorks program and the Flow Simulation simulation, and the velocity and pressure velocity fields of the vortex fluxes of the coolant were studied (Fig. 3). By setting different combinations of charges of the drying agent at the inlet of branch pipes 1 and 5 , one can determine the nature of the movements of the drying agent in the cell of the apparatus.

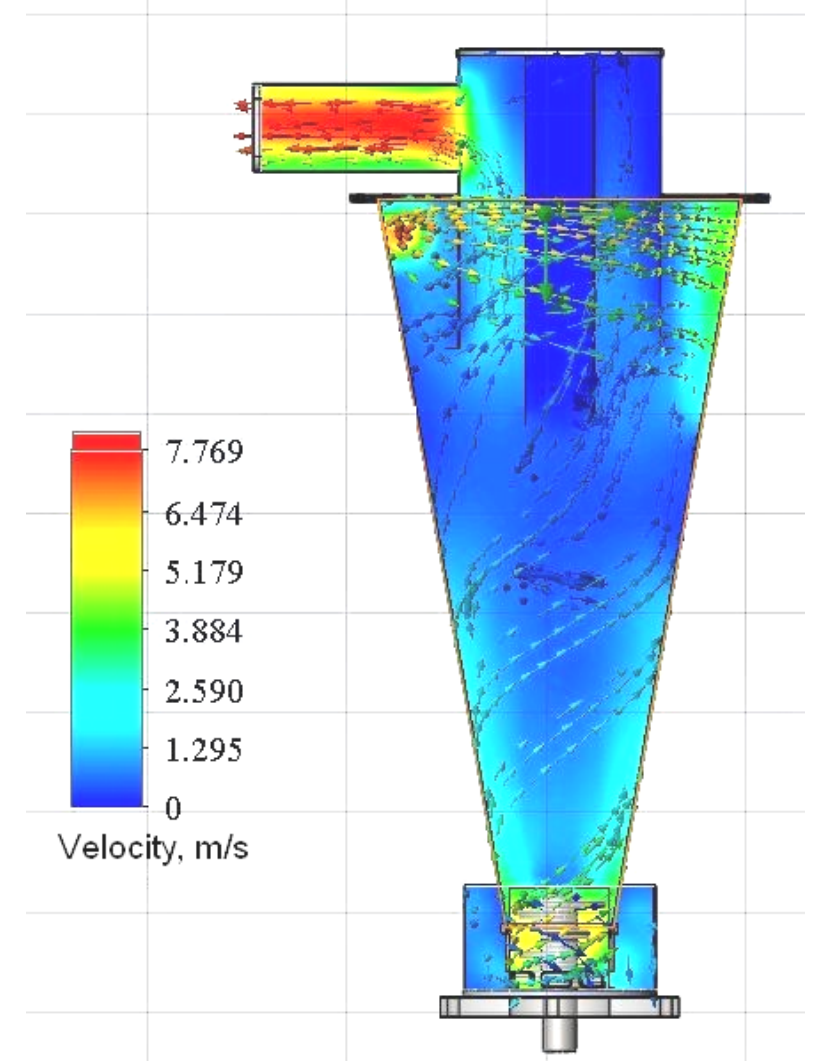

Figure 3. Study of vortex flows for expenses $20 \mathrm{~m}^{3} / \mathrm{s}$ for the bottom of the chamber and $80 \mathrm{~m}^{3} / \mathrm{s}$ for the upper part of the chamber

As can be seen from the diagram of the distribution of flows, the speed of the drying agent is divided into two components: axial and tangential. The axial speed is centered around the drying chamber, and which transports the finely divided particles of the material from the grinding zone to the drying zone and removes from the chamber. The tangential velocity of the gas phase is concentrated on the periphery of the drying chamber and separates the particles of the material and increases the heat transfer efficiency between the particles and the coolant due to the turbulence of the common two-phase flow and the increase of the Re number. The tangential velocity of the vortex stream decreases as a result of decreasing the radius of the drying chamber. The swirling coefficient of the vortex flows is the ratio of the tangential velocity to the axial and is 5.5-7.0 for this configuration of the drying chamber, which is almost the same as in the similar constructions that were considered in the works [7,9]. 


\section{Physical modeling of $\mathrm{TiO}_{2}$ paste drying process in a vortex dryer}

Fine particles of titanium dioxide powder are presented in the form of crystals (Fig. 4). The sizes of crystals depend on the technological conditions of crystallization of the product. Fine particles should have a size of $0.22-0.25$ microns [11]. When mixed with water, particles of $\mathrm{TiO}_{2}$ form a thyrotrophic paste that, when applied mechanically, reduces its viscosity and increases its fluidity.
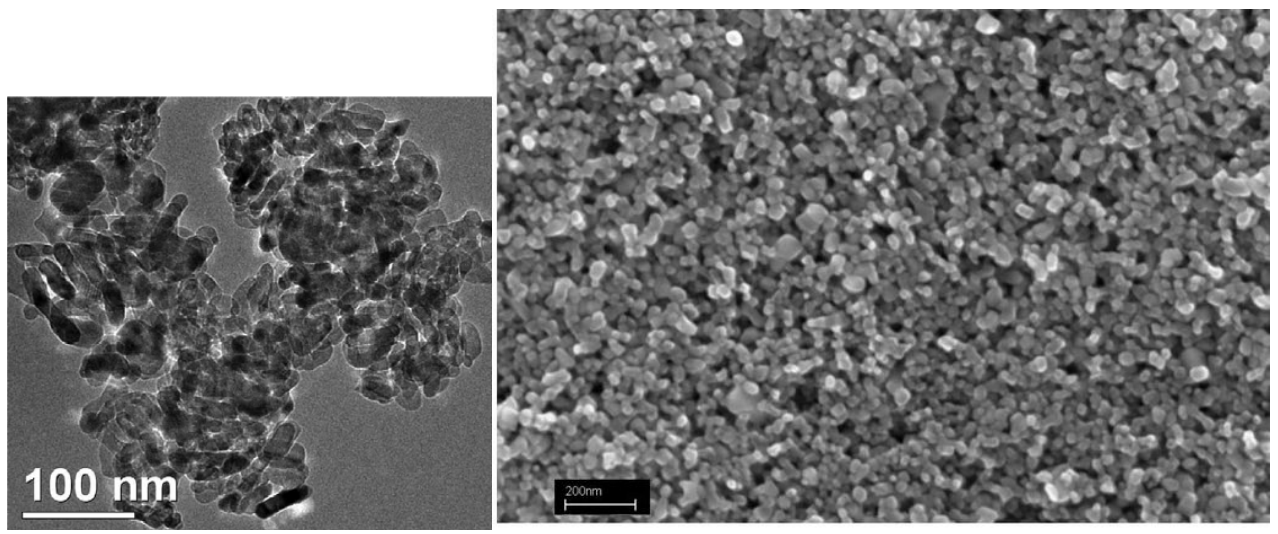

Figure 4. Crystal origin of finely divided particles of titanium dioxide [12]

As can be seen from Figure 4, crystals are chaotic, so thin channels, educations; cavities are formed between them, which fill up with water, forming a heterogeneous substance - a paste. Within the paste crystals are held by the forces of surface tension of water. In addition to the surface tension of additional forces, the interaction between the crystals is not present. When drying paste of $\mathrm{TiO}_{2}$ in vortex streams after removing all moisture, the paste turns into a fine pigment.

Moisture in the paste of $\mathrm{TiO}_{2}$ exists in such species:

- capillary moisture on the surface of agglomerates (Figure 5);

- micro capillary moisture;

- adsorption-bound moisture, moisture on the surface of the crystals;

- nanocapillary moisture.

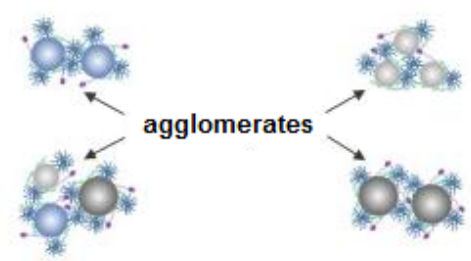

Figure 5. Titanium dioxide paste agglomerates [12]

In this work, the drying of the fine paste occurs in the vortex flow of the coolant, which has many significant advantages over conductive, spray drying or drying on inert bodies.

The speed of the drying process depends on the internal structure of the disperse material, its thermo physical properties, the size, shape and condition of the outer surface, 
the degree of grinding agglomerates of the paste, as well as the parameters of the drying agent (Figure 6). Parameters of the drying agent are: temperature, relative humidity, amount of heat and its consumption. When drying, the process of submerging the localized front of moisture evaporation into the middle of the agglomerates of the paste $\mathrm{TiO} 2$ passes, and the heat is supplied by the heat conductivity of the dry material and is spent on the conversion of moisture into the vapor.

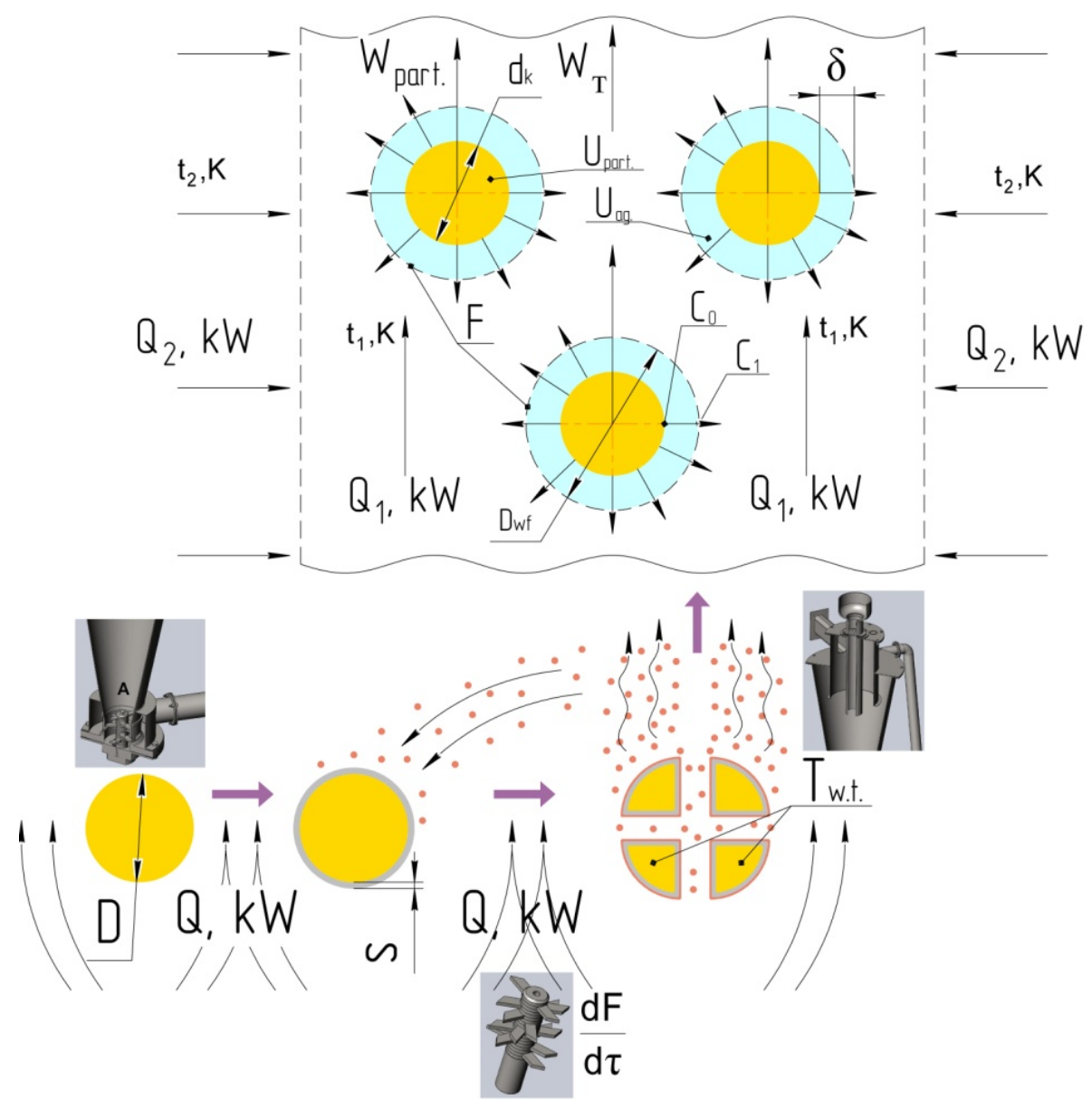

Figure 6. Physical model of drying of $\mathrm{TiO}_{2}$ paste conglomerates

Due to the evaporation of moisture inside the material, an excess pressure is formed through which the steam formed is filtered from the evaporation front to the outer surface of the wet body.

\section{Mathematical description of the process of drying of finely divided paste of titanium dioxide}

Thermal balance of the drying process: 


$$
d Q=d Q_{1}-d Q_{2}
$$

where $d Q$ heat flow to heat paste, $\mathrm{kJ} ; d Q_{1}$ convective heat flow from the drying agent, $\mathrm{kJ}$; $d Q_{2}$ heat flux on the evaporation of water from the paste of titanium dioxide, $\mathrm{kJ}$.

By drawing the constituents of the equation (1), we obtain:

$$
G_{\text {mat. }} \cdot\left(c_{\text {mat. }}+c_{w} \cdot U\right) \cdot d t_{\text {part. }}=\alpha \cdot F_{\text {part. }} \cdot\left(t_{\text {ag. }}-t_{\text {part. }}\right) \cdot d \tau-G_{\text {mat. }} \cdot \frac{d U}{d \tau} \cdot r \cdot d \tau
$$

where $G_{\text {mat. }}$ the mass flow of a completely dry powder of titanium dioxide, $\frac{\mathrm{kg}}{\mathrm{s}} \mathrm{w}$ speed of the drying agent (air), $\frac{m}{s} l$ the equivalent diameter of the particle of titanium dioxide paste, $\mathrm{m} ; v_{a g}$. kinematic viscosity of the drying agent, $\frac{m^{2}}{s} c_{\text {mat. }}$ specific heat of a titanium dioxide powder, $\frac{\mathrm{J}}{\mathrm{kg} \cdot \mathrm{K}} c_{w}$ specific heat of water, $\frac{\mathrm{J}}{\mathrm{kg} \cdot \mathrm{K}}$

$U$ moisture content of titanium dioxide, $\frac{\mathrm{kg}}{\mathrm{kg}} \alpha$ coefficient of heat transfer from the coolant to the surface of the particle, $\frac{W}{m^{2} \cdot K} F_{\text {part. }}$ outer surface of the particle, $m^{2}$; temperature of the drying agent, ${ }^{\circ} \mathrm{C}$; particle temperature, ${ }^{\circ} \mathrm{C}$; drying speed, $\frac{1}{S} r$ specific heat of steam generation, $\frac{J}{\mathrm{~kg}} d \tau$ drying time, s;

Drying rate in the first period is limited by the rate of heat transfer from the coolant to the lumps of paste [2]:

$$
\frac{d U}{d \tau}=\frac{\alpha \cdot\left(t_{a g .}-t_{w . t .}\right)}{r}
$$

in the second period, the water evaporates, bound by the adsorption forces [2]:

$$
\frac{d U}{d \tau}=-K \cdot\left(U_{1 k}-U\right)
$$

де $t_{\text {w.t. }}$ temperature of the wet thermometer, ${ }^{\circ} \mathrm{C} K$ drying rate, $\frac{1}{s} U_{1 k}$ critical moisture content, $\frac{\mathrm{kg}}{\mathrm{kg}} U$ equilibrium moisture content, $\frac{\mathrm{kg}}{\mathrm{kg}}$ On the basis of the thermal energy equation (2), the mathematical description of the drying process can be represented by the following system of equations: 


$$
\begin{aligned}
& \text { Processes and Equipment- } \\
& \left\{\begin{array}{c}
\frac{d t_{\text {part. }}}{d \tau}=\frac{\alpha \cdot F_{\text {part. }} \cdot\left(t_{\text {ag. }}-t_{\text {part. }}\right)}{G_{\text {mat. }} \cdot\left(c_{\text {mat. }}+c_{w} \cdot U\right)}-\frac{\frac{d U}{d \tau} \cdot r}{c_{\text {mat. }}+c_{w} \cdot U} \\
\frac{d U}{d \tau}=\frac{\alpha \cdot\left(t_{\text {ag. }}-t_{w . t .}\right)}{r}-K \cdot\left(U_{1 k}-U\right)
\end{array}\right.
\end{aligned}
$$

We accept the initial conditions for this system of equations (5):

$$
\begin{gathered}
\left.u\right|_{\tau=0}=u_{0}, u_{2}=u_{1 c r}, \tau_{0}=0, t_{0}=t_{1}, d_{0}=1 \mathrm{~mm}, \\
\left.\left.\alpha=\frac{N u \cdot \lambda_{a g .}}{D} 1\right], N u=0,021 \cdot \operatorname{Re}^{0,8} \cdot \operatorname{Pr}^{0,43} \cdot\left(\frac{P r}{P r_{p l .}}\right)^{0,25} \cdot \varepsilon 1,2\right],
\end{gathered}
$$

The mathematical description of the process of drying the titanium dioxide paste is solved by direct integration of the system of equations (5) using the initial conditions (6). The results of calculations are shown in Figures 2 and 3.

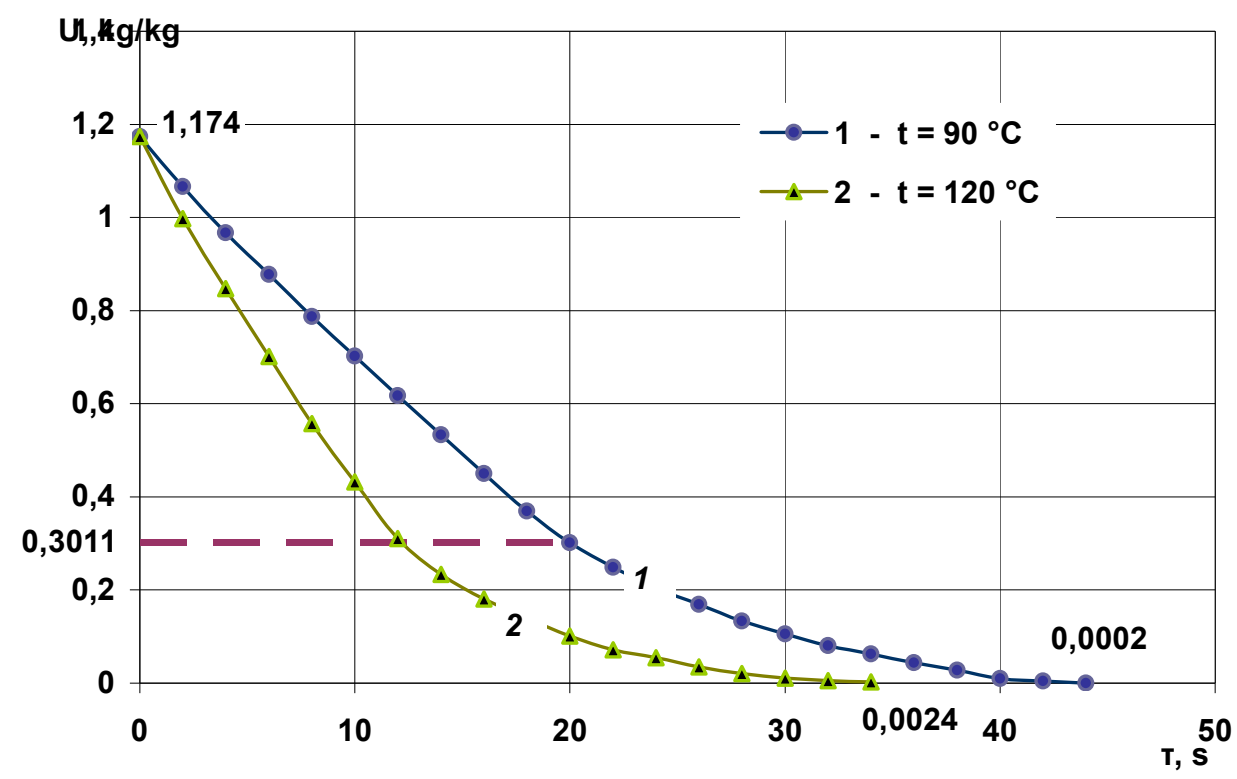

Figure 7. The dependence of the moisture content of the particle of titanium dioxide from the time of drying 


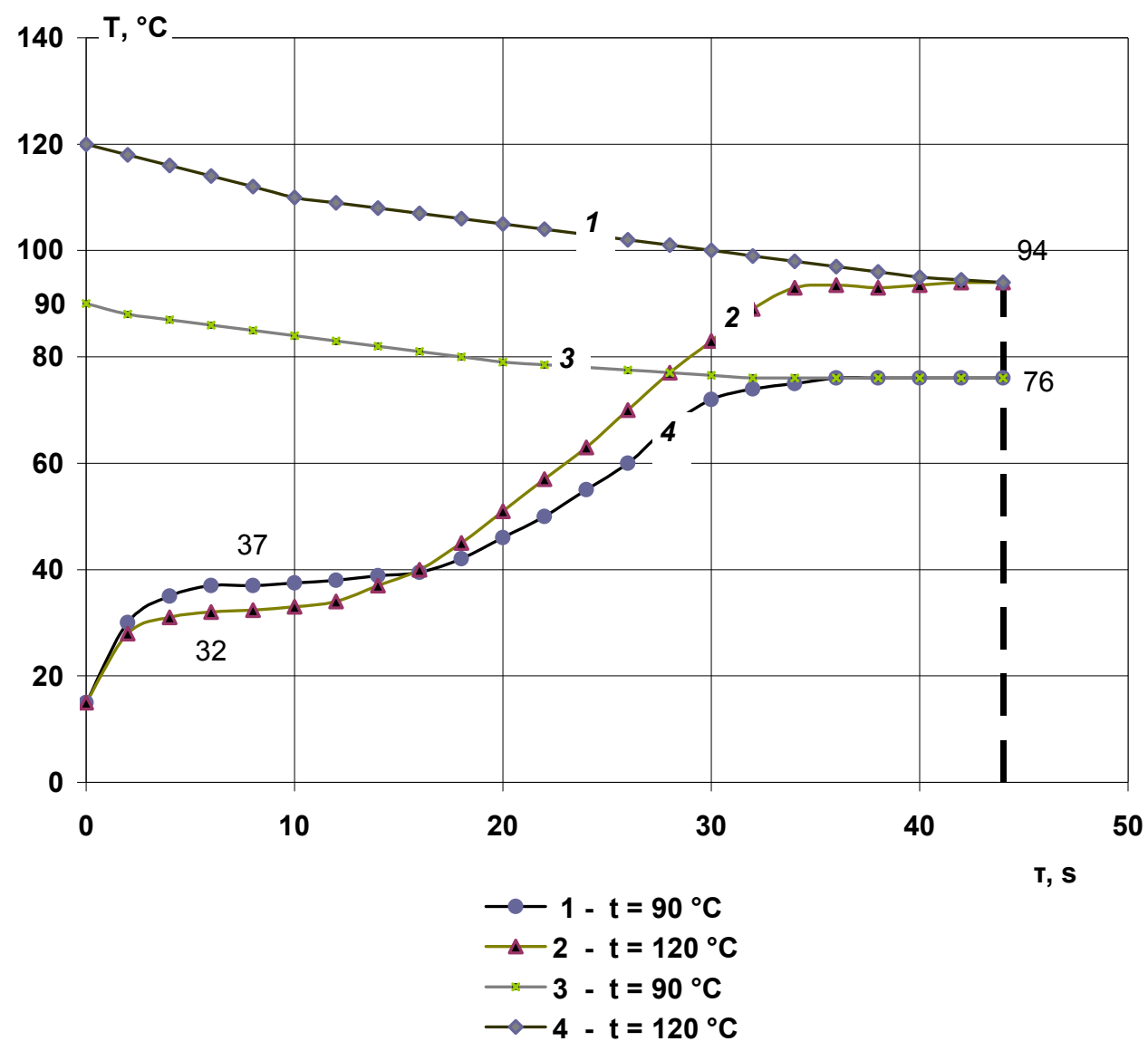

Figure 8. Dependence of the temperature of the particle of titanium dioxide from the time of drying

The dependence of the moisture content on time indicates that the drying process of the paste includes the period of heating to the temperature of the wet thermometer, the period of constant drying rate flowing in the range from $U_{1}=1,174 \frac{\mathrm{kg}}{\mathrm{kg}}$ to $U_{1 \mathrm{cr}}=0,3011 \frac{\mathrm{kg}}{\mathrm{kg}}$ and the period of the falling rate of drying, proceeding from $U_{1 \mathrm{cr}}=0,3011 \frac{\mathrm{kg}}{\mathrm{kg}}$ to $U_{2}=0,002 \frac{\mathrm{kg}}{\mathrm{kg}}$. Figure 2 shows that the limiting stage of the drying process is a period of falling velocity in which the adsorbed moisture is dried.

Figure 3 shows that the temperature mode of drying in the period of constant drying rate is stable. The temperature of the layer at the end of this period sharply rises to equilibrium with the temperature of the coolant. 


\section{Conclusions}

The mathematical process of drying fine titanium dioxide paste has been developed, which allows us to obtain the kinetic parameters of the process that are necessary for the design of an industrial drying apparatus. With the help of the developed design of the laboratory drying apparatus, the ability to dry the paste of $\mathrm{TiO}_{2}$ to a high residual dryness of $99.7 \%$ and the production of fine pigment was experimentally confirmed.

\section{References}

1. Marcus R., Leung L., Klinzing G., Rizk F. (1990), Pneumatic Conveying of Solids: A Theoretical and Practical Approach, 1st Ed, Powder Technology Series, Great Britain.

2. Pecora A., Goldstein L., Lombardi G., Pagliuso J. (1994), New particulate solids pneumatic feeding device with mass flowrate control, Powder Technology, Great Britain.

3. Pugsley T., Milne B., Berruti F. (1996), An innovative non-mechanical solids feeder for high solids mass fluxes in circulating fluidized beds, Powder Technology Journal, 2, pp. 123-131.

4. Ferreira M., Freire, J. (1992), Fluid dynamics characterization of a pneumatic bed with a spouted bed type solid feeding system, The Canadian Journal of Chemical Engineering, 7, pp. 905-909.

5. Littman H., Morgan M., Paccione J., Jovanovic S., Grbavic Z. (1993), Modeling and measurement of the effective drag coefficient in decelerating and non-accelerating turbulent gassolids dilute phase flow of large particles in a vertical transport pipe, Powder Technology Journal, 5, pp. 267-283.

6. Costa I., Ferreira M., Freire, J. (2004), Analysis of regime transitions and flow instabilities in vertical conveying if coarse particles using different solids feeding systems, The Canadian Journal of Chemical Engineering, 3, pp. 48-59.

7. Markowski A. (1992), Drying Characteristics in a Jet spouted Bed Dryer, Can. J. Chem. Eng., 5, pp. 156-163.

8. Barret N., Fane A. (1990), Drying Liquid Materials in a Spouted Bed, New York Hemisphere Publ, 8, pp. 278-286.

9. Jong J., Hoffmann A., Finkers H. (1999), Properly Determine Powder Flowability to Maximize Plant Output, Chem. Eng. Prog., 4, pp. 135-142.

10. Grobovenko Y., Marchevskii V. (2017), Modeliuvannia protsesu sushinnia dribnodyspersnykh chastynok $\mathrm{TiO}_{2}$ v pototsi sushylnoho ahentu, Visnyk Natsionalnoho tekhnichnoho universytetu Ukrainy "KPI", Khimichna inzheneriia ekolohiia ta resursozberezhennia, 1, pp. 78-81.

11. Grobovenko Y., Marchevskii V. (2018), Aerodynamika vykhrovykh potokiv sushylnoho ahentu u sushylnii kameri. Visnyk Zhytomyrskoho derzhavnoho tekhnolohichnoho universytetu, seriia "Tekhnichni nauky", 1, pp. 22-25.

12. Grobovenko Y., Marchevskii V. (2016), Protses sushinnia pasty dioksydu tytanu u vykhrovomu sushylnomu aparati, Naukovyi zhurnal "Smart and young", 11-12, pp. 55-58.

13. Dmitriev V. (2013), Konvektivnaya sushka polidispersnykh materialov v apparatakh zakruchennogo vzveshennogo sloya, Vestnik Tambovskogo gosudarstvennogo tekhnicheskogo universiteta, 3, pp. 602-606.

14. Adamiec J. (2002), Drying of waste sludges in a fluidized bed dryer with a mixer, Drying Technology, 20, p. 839.

15. Bait R., Pawar S., Banerjee A., Mujumdar A., Thorat B. (2011), Mechanically agitated fluidized bed drying of cohesive particles at low air velocity, Drying Technology, 29, p. 808.

16. Puspasari I., Talib M., Daud W., Tasirin S. (2012), Drying kinetics of palm oil frond particles in an agitated fluidized bed dryer, Drying Technology, 30, p. 619.

17. Chongdian S., Wu J., Wang Y., Zhang Y., Shang X. (2015), Drying of low rank coals: A review of fluidized bed technologies, Drying Technology, 33, p. 277.

18. Kim J., Han G. (2006), Effect of agitation on fluidization characteristics of fine particles in a fluidized bed, Powder Technology, 166, p. 113. 